\title{
An Effective Method for Parameter Estimation of Solar PV Cell Using Grey-Wolf Optimization Technique
}

\author{
Abhishek Sharma \\ Research and Development Department, \\ University of Petroleum and Energy Studies, Dehradun, Uttarakhand, India. \\ Corresponding author: abhishek15491@gmail.com \\ Abhinav Sharma \\ Department of Electrical and Electronics Engineering, \\ University of Petroleum and Energy Studies, Dehradun, Uttarakhand, India. \\ E-mail: abhinavgbpuat@gmail.com \\ Averbukh Moshe \\ Department of Electrical and Electronics Engineering, \\ Ariel University, Ariel, Israel. \\ E-mail: mosheav@ariel.ac.il \\ Nikhil Raj \\ Research and Development Department, \\ University of Petroleum and Energy Studies, Dehradun, Uttarakhand, India. \\ E-mail: nikhil.raj110@gmail.com \\ Rupendra Kumar Pachauri \\ Department of Electrical and Electronics Engineering, \\ University of Petroleum and Energy Studies, Dehradun, Uttarakhand, India. \\ E-mail: rpachauri@ddn.upes.ac.in
}

(Received on November 21, 2020; Accepted on February 7, 2021)

\begin{abstract}
In the field of renewable energy, the extraction of parameters for solar photovoltaic (PV) cells is a widely studied area of research. Parameter extraction of solar PV cell is a highly non-linear complex optimization problem. In this research work, the authors have explored grey wolf optimization (GWO) algorithm to estimate the optimized value of the unknown parameters of a PV cell. The simulation results have been compared with five different pre-existing optimization algorithms: gravitational search algorithm (GSA), a hybrid of particle swarm optimization and gravitational search algorithm (PSOGSA), sine cosine (SCA), chicken swarm optimization (CSO) and cultural algorithm (CA). Furthermore, a comparison with the algorithms existing in the literature is also carried out. The comparative results comprehensively demonstrate that GWO outperforms the existing optimization algorithms in terms of root mean square error (RMSE) and the rate of convergence. Furthermore, the statistical results validate and indicate that GWO algorithm is better than other algorithms in terms of average accuracy and robustness. An extensive comparison of electrical performance parameters: maximum current, voltage, power, and fill factor (FF) has been carried out for both PV model.
\end{abstract}

Keywords- Photovoltaic, GWO, Parameter extraction, Single-diode model, Double-diode model.

\section{Introduction}

The depletion of fossil fuel resources and resulting environmental impact due to their usages embarks the need for alternate energy resources (Panwar et al., 2011; Tao et al., 2020). Solar energy 
International Journal of Mathematical, Engineering and Management Sciences

Vol. 6, No. 3, 911-931, 2021

https://doi.org/10.33889/IJMEMS.2021.6.3.054

is one of the most promising alternate sources for fossil fuel. The free to access the energy of sunlight can be well extracted by means of solar photovoltaic panels. The rapid adoption of solar energy by domestic and industrial sector makes it a vital source to be explored (Gielen et al., 2019). Enormous researches have been performed and is being carried out for the betterment of the power output from the PV panels (Jordehi, 2016; Rhouma et al., 2017) . Despite the very low operational and maintenance cost, it has various limitations associated with it. The major limitation in the execution and implementation of the solar PV power plants are very high capital cost for installation (Aryanpur et al., 2019) . Taking into consideration the operational limitations and non-linear nature of characteristics of solar PV modules (Armghan et al., 2018). This non-linearity makes it difficult for any probability and approximation to increase the efficiency (Sharma et al., 2021). Every PV panels is designed to operate at maximum efficiency, as defined by the manufacturer, only if the practical operational parameters are somewhat close to or coinciding with the maximum power point (MPP) (Esram and Chapman, 2007; Liu et al., 2016; Mohapatra et al., 2017). The dynamic behaviour, due to the non-linearity of I-V characteristics of solar cells make it essential to determine the MPP through simulation techniques for better operational efficiency (Ram et al., 2018). The parameters provided by the PV panel manufacturer don't specifies the model parameters. The given information states the open circuit voltage $\left(\mathrm{V}_{\mathrm{oc}}\right)$, short circuit current $\left(\mathrm{I}_{\mathrm{sc}}\right)$ and current at maximum power point $\left(\mathrm{I}_{\mathrm{mpp}}\right)$ under standard test conditions (i.e., $1000 \mathrm{~W} / \mathrm{m}^{2}, 25^{\circ} \mathrm{C}$ ). The practical parameters vary at every instant with a change in weather condition and the aging effect of PV also alters the parameters (Gomes et al., 2016; Jordehi, 2016; Youssef et al., 2017).

The core unit of PV system is solar cell, and it is of utmost priority to extract the parameters for a close analysis of the PV panels performance around its MPP. The simulation study of cells combined all together give the performance analysis of entire PV panels (Chin et al., 2015; Youssef et al., 2017) . The equivalent circuit for single and double diode model for parameter extraction is the recent and most widely used approach. The method of parameter extraction can be bifurcated in two major categories: analytical and optimization methods (Brano and Ciulla, 2013; Batzelis and Papathanassiou, 2015; Louzazni and Aroudam, 2015; Khan et al., 2016). Although the analytical methods are the simplest and yields result quickly, but it misses the accuracy under normal day conditions with variable lighting. The deterministic ways of parameter extraction such as NewtonRaphson, non-linear least square, Lambert W-functions (Gao et al., 2016), iterative curve fitting (Villalva et al., 2009), conductivity method (Chegaar et al., 2001), levenberg-Marquardt algorithm (Ma et al., 2014) are having many boundaries such as continuity, differentiability and convexity related to objective functions. The boundary conditions further impose limitations on the usage of the above analytical methods, as they obtain local minima when dealing with multi-modal problems. Thus, analytical methods are not suitable enough to extract the parameters.

To get more accurate and precise parameters from nonlinear implicit equations with high accuracy, evolutionary algorithms (Coello et al., 2007) were proposed. The bio related algorithms are more accurate and powerful optimization algorithms to simplify nonlinear transcendental equations as it doesn't include complex mathematics. Some of the recent optimization algorithms used for the parameter extraction are genetic algorithm (GA) (Ismail et al., 2013), differential evolution(DE) (Ishaque et al., 2012), simulated annealing(SA) (El-Naggar et al., 2012), pattern search (PS) (ElNaggar et al., 2012), harmony search (HS) (Askarzadeh and Rezazadeh, 2012), cuckoo search(CS) (Ma et al., 2013), flower pollination algorithm (Alam et al., 2015), bacterial foraging optimization (BFO) (Subudhi and Pradhan, 2017), bird mating (Askarzadeh and Rezazadeh, 2013b), artificial bee swarm optimization (ABSO) (Askarzadeh and Rezazadeh, 2013a), chicken swarm optimization (CSO) (Sharma et al., 2019) and particle swarm optimization (PSO) (Khanna et al., 2015). The 
International Journal of Mathematical, Engineering and Management Sciences

Vol. 6, No. 3, 911-931, 2021

https://doi.org/10.33889/IJMEMS.2021.6.3.054

proposed algorithms suffer with the problem of premature convergence. The primary disadvantage of GA is that it involves wide parameter optimization search space which makes the system quite complicated and slow. The problem of large search space was overcome by implementing PSO. However, it imposed the problem of randomly chosen initial parameter value. The value exchange in SA between the cooling timetable and the original temperature makes it less popular. There is a likelihood that PS will choose an incorrect pattern, leading to premature convergence or no convergence. PSO with reverse barrier restriction for $\mathrm{R}_{\mathrm{s}}, \mathrm{R}_{\mathrm{sh}}$, and a is suggested for fast and coherent convergence of optimization issue to global optima, considering the temperature impact to reduce the modelling errors in differential evolution (Soon and Low, 2012). Although the BFO technique offers excellent outcomes but involving too many parameters has complicated the scheme and imposed a computational strain. Authors in (Li et al., 2019), implemented improved teaching learning based optimization (ITLBO), where a good trade-off is established between exploration and exploitation by eliminating the worse learner. This increases the global search ability of the population in defined search space. A hybridization approach is carried out by the researchers (Beigi and Maroosi, 2018) for parameter extraction of solar PV cell. In this approach hybridization of two algorithms: firefly and pattern search are implemented. The exploration phase is completed by the firefly algorithm during first half iteration and then pattern search algorithm takes control of population for the exploitation phase. A new opposition-based learning approach is incorporated with whale optimization and shuffled complex evolutionary algorithm for optimization of solar cell parameters (Elaziz and Oliva, 2018; Chen et al., 2019). This approach is tested on unimodal as well as on multimodal benchmark functions and simulation results clearly shows the robustness of the algorithms.

The GWO possess various advantages over the other existing optimization algorithms. It is an easy computational algorithm with reduced burden of computation. The application flexibility for parameter extraction problem without any deep change in existing structure, makes it more usable. The problem of convergence and local optima was also avoided. The most interesting aspect with respect to applicability of this optimization technique is that concept can easily be transformed into programming language for the real time implementation. Tsai and Dao (2016) implemented GWO algorithm for path planning of mobile robot in static environment. Multi-objective function was used for smoothness of path and obstacle avoidance. Simulation results depicted that anticipated approach was able to generate the optimal path from starting position to target position with obstacle avoidance. Lu et al. (2016) have proposed a separate multi-objective GWO to improve the real-world scheduling case from a welding cycle. The experiment and the statistical analysis depicted the superiority of the GWO over the non-sorting genetic algorithm (NSGA-II) and the Pareto evolutionary algorithm. In the field of Bioinformatics, Jayapriya and Arock (2015) used a parallel model of GWO for problem alignment of multiple sequences. Their method proved the effectiveness of anticipated algorithm in terms of time-complexity. In this paper authors have implemented the grey wolf optimization (GWO) algorithm to estimate the optimized value of parameters for PV cells. In order to validate the performance and precision of the GWO technique, the results are compared with well know pre-existing algorithms in the literature. This paper presents five parameter extraction for single diode and seven parameters extraction for double diode equivalent circuit of solar PV cell.

The organization of paper as follows: the problem formulation and mathematical model for solar PV cell is presented in section 2. In section 3 authors gave a brief introduction of GWO algorithm and discussed its implementation to estimate the optimized value of unknown parameters of single and double diode model. In section 4 simulation results of GWO algorithm are discussed and 
compared with pre-existing metaheuristic algorithm. Finally, section 5 gives a conclusive remark to summarize the paper.

\subsection{Novelty of Work}

The GWO based optimization technique reduces the root mean square error (RMSE) to 9.4094E04 and 1.2450E- 03 in the case of single diode model and double diode model respectively. The parameters optimized by the GWO algorithm improves the performance of PV system in terms of maximum power and fill factor (FF) as compared with other algorithms. The GWO algorithm is a robust optimization technique for solar PV parameter extraction due to following factors:

- There is a good trade-off between exploration and exploitation phase in GWO algorithm.

- GWO has the least value of RMSE as compared with GSA, PSOGSA, SCA, CSO and CA algorithms.

Extensive comparison of $\mathrm{I}_{\mathrm{m}}, \mathrm{V}_{\mathrm{m}}, \mathrm{P}_{\mathrm{m}}$ and $\mathrm{FF}$ performance is carried out based on estimated parameters.

\section{Problem Formulation}

In this section, the equivalent circuits of a photovoltaic solar cell are formulated using single diode and double diode models. These equivalent circuit models are used to describe the current-voltage characteristics of a solar cell.

\subsection{Single-Diode Model for PV Cell}

The equivalent circuit of single-diode model is depicted in Figure 1. The relation between current and voltage at output terminal is expressed as follows (Al-Rashidi et al., 2011; Gong and Cai, 2013):

$I_{l}=I_{p}-I_{d 1}-I_{s h}$

where, $I_{l}$ stands for cell current in output, $I_{p}$ represents the photogenerated current, $I_{d 1}$ stands for diode current, $I_{s h}$ represents the current flowing through parallel resistance.

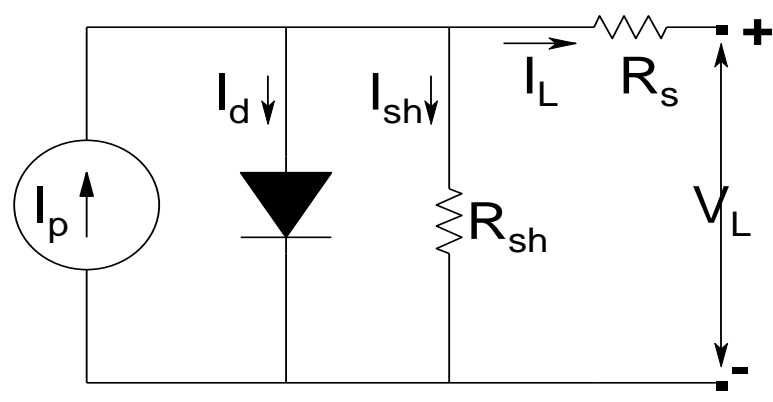

Figure 1. Equivalent circuit of single diode model for PV cell.

As per Shockley equation, the diode current is expressed as: 
$I_{d 1}=I_{S D}\left[\exp \left(\frac{q\left(V_{l}+I_{l} R_{S}\right)}{a_{1} k_{B} T}\right)-1\right]$

where, $I_{S D}, V_{l}, a_{1}, R_{S}, k_{B}, \mathrm{~T}$ and $q$ are reverse saturation current, cell output voltage, diode ideality constant, series resistance, the Boltzmann constant $(1.3806503 \times 1023 \mathrm{~J} / \mathrm{K})$, junction temperature $\left({ }^{\circ} \mathrm{K}\right)$ and the electron charge $\left(1.60217646 \times 10^{-19} \mathrm{C}\right)$, respectively. The current flowing through shunt resistance can be described as follows:

$I_{s h}=\frac{V_{l}+I_{l} R_{S}}{R_{s h}}$

where, $R_{s h}$ stands for shunt resistance.

By merging equations (1)-(3), we arrive at:

$I_{l}=I_{p}-I_{S D}\left[\exp \left(\frac{q\left(V_{l}+I_{l} R_{S}\right)}{a_{1} k_{B} T}\right)-1\right]-\frac{V_{l}+I_{l} R_{S}}{R_{S h}}$

In above equation, five model parameters $\left(I_{p}, I_{S D}, a_{1}, R_{s}\right.$ and $\left.R_{s h}\right)$ are needed to be optimized using measured I-V data of the solar cell. The SDM is considered good and easy to regenerate the I-V curve. However, this model lacks the phenomena of the recombination effect in the diode, that is why it is not the most suitable model.

\subsection{Double Diode Model for PV Cell}

Figure 2 depicts the double diode model for PV cell. The double diode model (DDM) is considered precise and complicated than that of single diode model (SDM). The relation between current and voltage at output terminal for the DDM is expressed as (AlRashidi et al., 2011; Gong and Cai, 2013):

$$
\begin{aligned}
& I_{l}=I_{p}-I_{d 1}-I_{d 2}-I_{S h} \\
& =I_{p}-I_{S D 1}\left[\exp \left(\frac{q\left(V_{l}+I_{l} R_{S}\right)}{a_{1} k_{B} T}\right)-1\right]-I_{S D 2}\left[\exp \left(\frac{q\left(V_{l}+I_{l} R_{S}\right)}{a_{2} k_{B} T}\right)-1\right]-\frac{V_{l}+I_{l} R_{S}}{R_{S h}}
\end{aligned}
$$

where, $I_{S D 1}$ and $I_{S D 2}$ represents the diffusion and saturation current respectively. $I_{d 1}$ and $I_{d 2}$ represents the first and second diode current. Eqn. (5) defines seven unknown model parameters: $I_{p}, I_{S D 1}, I_{S D 2}, a_{1}, a_{2}, R_{S}$ and $R_{S h}$, which are required to be optimized using experimental data of current and voltage for the solar cell.

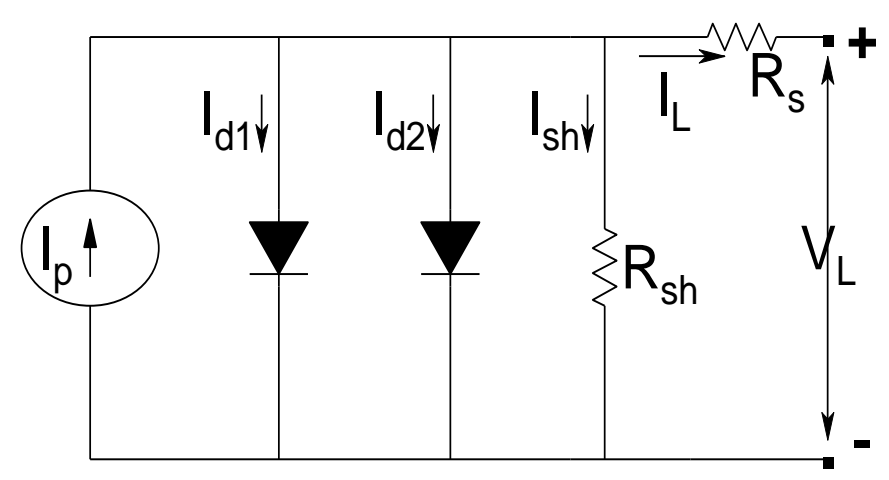


International Journal of Mathematical, Engineering and Management Sciences

Vol. 6, No. 3, 911-931, 2021

https://doi.org/10.33889/IJMEMS.2021.6.3.054

Figure 2. Equivalent circuit of double diode model for PV cell.

\subsection{Objective Function}

The key purpose of this work is to optimize the unknown parameters for both the models (SDM and DDM) and to reduce the error between experimental and estimated data (Rezk et al., 2021). The objective function for error is formulated as:

$R M S E=\sqrt{\frac{1}{k} \sum_{N=1}^{k} f}\left(V_{l}, I_{l}, X\right)$

where, $V_{l}$ and $I_{l}$ are the measured voltage and current of PV module. The parameter ' $\mathrm{k}$ ' stands for the number of experimental data set. The best solution found by GWO is represented by a vector $\mathrm{X}$.

For the single diode model,

$$
\left\{\begin{array}{c}
f_{\text {single }}\left(V_{l}, I_{l}, X\right)=I_{p}-I_{S D}\left[\exp \left(\frac{q\left(V_{l}+I_{l} R_{S}\right)}{a_{1} k_{B} T}\right)-1\right]-\frac{V_{l}+I_{l} R_{S}}{R_{S h}}-I_{l} \\
\left(X=I_{p}, I_{S D}, a_{1}, R_{S}, R_{S h}\right)
\end{array}\right.
$$

For the double diode model,

$$
\left\{\begin{array}{c}
f_{\text {double }}\left(V_{l}, I_{l}, X\right)=I_{p}-I_{S D 1}\left[\exp \left(\frac{q\left(V_{l}+I_{l} R_{S}\right)}{a_{1} k_{B} T}\right)-1\right] \\
-I_{S D 2}\left[\exp \left(\frac{q\left(V_{l}+I_{l} R_{S}\right)}{a_{2} k_{B} T}\right)-1\right]-\frac{V_{l}+I_{l} R_{S}}{R_{S h}}-I_{l} \\
\left(X=I_{p}, I_{S D 1}, I_{S D 2}, a_{1}, a_{2}, R_{S}, R_{S h}\right)
\end{array}\right.
$$

\section{Metaheuristic Algorithms}

In the field of computer science and mathematical optimization, metaheuristic approaches have gained popularity over the last two decades. Glover (1986) coined the term metaheuristic which combines the Greek prefix meta (high level) and heuristic (to find/discover). These approaches are stochastic in nature and find the optimum solution with less computation effort as compared to conventional techniques. Metaheuristic approaches are problem independent and can be mainly classified into three different classes i.e., based on swarm intelligence, physics, and evolutionary concepts.

\subsection{GWO Based Optimization}

Grey wolf optimization proposed by Mirjalili et al. (2014) is a swarm intelligence technique which is originated from grey wolves. The behaviour of hunting and social hierarchy of grey wolves is mathematically defined in terms of an algorithm to solve high dimensional optimization problems. The leadership hierarchy of grey wolves are simulated by four types i.e., alpha $(\alpha)$, beta $(\beta)$, delta $(\delta)$ and omega $(\omega)$. These categories of grey wolves live on an average in a group of five to ten and present an important behaviour of group hunting. Mainly the hunting process is accomplished by $\alpha, \beta, \delta$ while $\omega$ tracks these three wolves. 
International Journal of Mathematical, Engineering and Management Sciences

Vol. 6, No. 3, 911-931, 2021

https://doi.org/10.33889/IJMEMS.2021.6.3.054

The three main stages of GWO are tracking, encircling, and hunting the prey which are depicted in Figure 3 and mathematically modeled as follows:

Step 1. Initiate the random population of grey wolves within defined search space:

$P_{i}=\left(p_{i}^{1} \ldots \ldots \ldots p_{i}^{j} \ldots \ldots p_{i}^{j}\right)$ for $i=1,2, \ldots \ldots \ldots, n$.

where, $p_{i}^{d}$ represents the location of $i^{\text {th }}$ particle in the $j^{\text {th }}$ dimension and $n$ signifies the dimension of search space.

Step 2. Calculate fitness of all search agents, if the problem is the minimization problem, the fittest (minimum) value of the fitness function is considered as $X_{\alpha}$, second and third minimum values are considered as $X_{\beta}, X_{\delta}$ respectively. The rest value of fitness functions is considered as $X_{\omega}$.

Step 3. There is an update in terms of the location of each search agents, in each iteration, according to the best search agents $\left(X_{\alpha}, X_{\beta}, X_{\delta}\right)$ using following equations:

$\vec{D}_{\alpha}=\left|\vec{C}_{1} * \vec{X}_{\alpha}-\vec{X}\right|, \quad \vec{D}_{\beta}=\left|\vec{C}_{2} * \vec{X}_{\beta}-\vec{X}\right|, \quad \vec{D}_{\delta}=\left|\vec{C}_{3} * \vec{X}_{\delta}-\vec{X}\right|$

$\vec{X}_{1}=\vec{X}_{\alpha}-\vec{A}_{1} *\left(\vec{D}_{\alpha}\right), \quad \vec{X}_{2}=\vec{X}_{\beta}-\vec{A}_{2} *\left(\vec{D}_{\beta}\right), \quad \vec{X}_{3}=\vec{X}_{\delta}-\vec{A}_{3} *\left(\vec{D}_{\delta}\right)$

$\vec{X}(k+1)=\frac{\vec{X}_{1}+\vec{X}_{2}+\vec{X}_{3}}{3}$

where, k signifies the current iteration, $\vec{A}_{1}, \vec{A}_{2}, \vec{A}_{3}$ and $\vec{C}_{1}, \vec{C}_{2}, \vec{C}_{3}$ are the coefficient vectors of alpha, beta and delta, and $\vec{X}$ denotes the location vector of grey wolf. The generalized expression of coefficient vectors $\vec{A}$ and $\vec{C}$ are defined as:

$\vec{A}=2 * \vec{a} * \vec{r}_{1}-\vec{a}$

$\vec{C}=2 * \vec{r}_{2}$

where, the component $\vec{a}$ is linearly reduced from 2 to 0 over the course of iterations and $r_{1}, r_{2}$ are the random vectors in the range $[0,1]$.

Step 4. Update the coefficient vectors $\vec{A}$ and $\vec{C}$ in each iteration.

Step 5. Calculates the fitness of each search agent and update $X_{\alpha}, X_{\beta}, X_{\delta}$ in each iteration.

Step 6. Jump to step 3 until the termination criteria is met. The algorithm stops at two conditions either at maximum number of iterations or the least error criteria is met.

Step 7. In the last iteration the returned value of $\vec{X}_{\alpha}$ represents the global minimum and the positions corresponding to it represents the solution of the problem. 


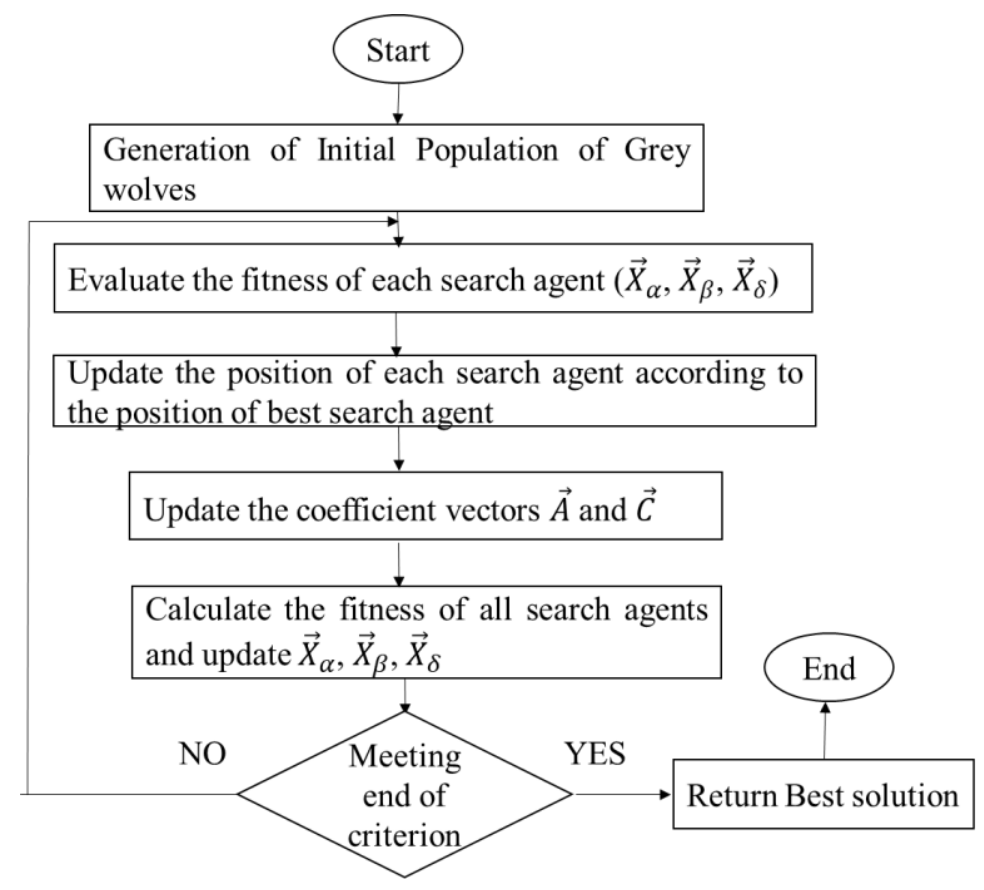

Figure 3. Flowchart of GWO algorithm.

\subsection{Implementation of GWO for Parameter Extraction}

\subsubsection{Single-Diode Model}

Step 1. Initialize the population of search agents of fifth order dimension in the search space. The fifth order dimension represents the photovoltaic current $\left(I_{p}\right)$, series resistance $\left(R_{s}\right)$, shunt resistance $\left(R_{s h}\right)$, diode saturation current $\left(I_{S D}\right)$ and diode ideality factor $\left(a_{1}\right)$. The range of these parameters are [0-1, 0.001-0.5, 0-100, 0.01-0.5, 1-2].

Step 2. Regulate the fitness of all agents in the search space using eq. (7).

Step 3. Update the position of the agents at every iteration using GWO. The algorithm is designed to work in the minimization mode thus the location of particles that acquire minimum cost represents the optimized parameters of SDM with minimum RMSE.

\subsubsection{Double-Diode Model}

Step 1. Initialize population of search agents of seventh order dimension in the search space. The seventh order dimension represents the photovoltaic current $\left(I_{p}\right)$, series resistance $\left(R_{s}\right)$, shunt resistance $\left(R_{S h}\right)$, diode saturation currents $\left(I_{S D}, I_{S D I}\right)$ and diode ideality factor $\left(a_{1}, a_{2}\right)$. The range of these parameters are $[0-1,0.001-0.5,0-100,0.01-0.5,0.01-0.5,1-2,1-2]$.

Step 2. Regulate the fitness of all agents in the search space using eq. (8).

Step 3. Update the position of all agents at every iteration using GWO. The algorithm is designed to work in the minimization mode thus the location of particles having minimum cost represents the parameters of double diode model with minimum RMSE. 
International Journal of Mathematical, Engineering and Management Sciences

Vol. 6, No. 3, 911-931, 2021

https://doi.org/10.33889/IJMEMS.2021.6.3.054

\section{Experimental Results and Discussion}

In this section, in order to check efficiency, the GWO optimization technique is implemented to optimize the two parameter extraction problems efficiently and derived from literature. These problems consider mainly two distinct cases: single diode and double diode model for a solar PV cell. The experimental observations of current and voltage for both considered case is taken from (Easwarakhanthan et al., 1986) where the dataset is measured from a $57 \mathrm{~mm}$ diameter industrial silicon solar cell with model name of R.T.C. France under STC (i.e. $1000 \mathrm{w} / \mathrm{m}^{2}$ and $33^{\circ} \mathrm{C}$ ). The measured data set consists of total 26 samples of voltage and current. For fair comparison the search ranges (i.e. upper and lower bound) for each individual parameter is tabulated in Table 1, that are same as already used by the researchers (AlHajri et al., 2012; Gong and Cai, 2013; Chen et al., 2016; Oliva et al., 2017). The upper and lower range of parameters is presented in Table 1.

To validate the effective performance in terms of convergence rate, robustness and quality of result, GWO is compared with five pre-existing and well established algorithms in the literature, they are PS (AlHajri et al., 2012), SA (El-Naggar et al., 2012), HS (Askarzadeh and Rezazadeh, 2012), PSO (Wei et al., 2011) and GA (Jervase et al., 2001). To perform the experiment, size of population and maximum number of objective function evaluations are kept at 30 and 50,000 respectively. In order to avoid the contingency total number of 30 independent runs are carried out. For testing and programming the algorithm, MATALB 2018 software is used to perform all the statistical test. Details of hardware and software is tabulated in Table 2.

Table 1. Range of parameters for SDM and DDM.

\begin{tabular}{|c|c|c|c|c|}
\hline \multirow{2}{*}{ Parameter } & \multicolumn{2}{|c|}{ SDM } & \multicolumn{2}{c|}{ DDM } \\
\cline { 2 - 5 } & Lower bound & Upper bound & Lower bound & Upper bound \\
\hline $\mathrm{I}_{\mathrm{p}}(\mathrm{A})$ & 0 & 1 & 0 & 1 \\
\hline $\mathrm{I}_{\mathrm{sd}}(\mu \mathrm{A})$ & 0.01 & 0.5 & 0.01 & 0.5 \\
\hline $\mathrm{R}_{\mathrm{s}}(\Omega)$ & $1 \mathrm{E}-03$ & 0.5 & $1 \mathrm{E}-03$ & 0.5 \\
\hline $\mathrm{R}_{\mathrm{sh}}(\Omega)$ & 0 & 100 & 0 & 100 \\
\hline $\mathrm{a}_{1}$ & 1 & 2 & 0.01 & 0.5 \\
\hline $\mathrm{I}_{\mathrm{sd} 1}(\mu \mathrm{A})$ & & & 1 & 2 \\
\hline $\mathrm{a}_{2}$ & & & 1 & 2 \\
\hline
\end{tabular}

Table 2. The specification of hardware used in simulating the system.

\begin{tabular}{|c|c|}
\hline Name & Configuration \\
\hline Hardware & Intel Core i7 \\
\hline CPU & 3.6 Giga Hertz \\
\hline Frequency & 8 Giga Byte \\
\hline RAM & 2 Tera Byte \\
\hline Hard Drive & Windows 10 \\
\hline Software & MATLAB 2018a \\
\hline Operating System & \\
\hline Language & \\
\hline
\end{tabular}


International Journal of Mathematical, Engineering and Management Sciences

Vol. 6, No. 3, 911-931, 2021

https://doi.org/10.33889/IJMEMS.2021.6.3.054

\subsection{Simulation Results for SDM}

There are only five parameters $\left(I_{p}, I_{s d}, a_{l}, R_{s}, R_{s h}\right)$ which are required to be optimized in the case of SDM. Table 3 represents the values of parameters optimized by GWO and RMSE, for the comparison. It can be clearly analysed that GWO produces the least RMSE of 9.4094E-04 which is very low as compared with the results of other five algorithms: GSA, PSOGSA, SCA, CSO and CA. Here RMSE values are acquired as the index for the evaluation of results with previously existing algorithms implemented by the researchers.

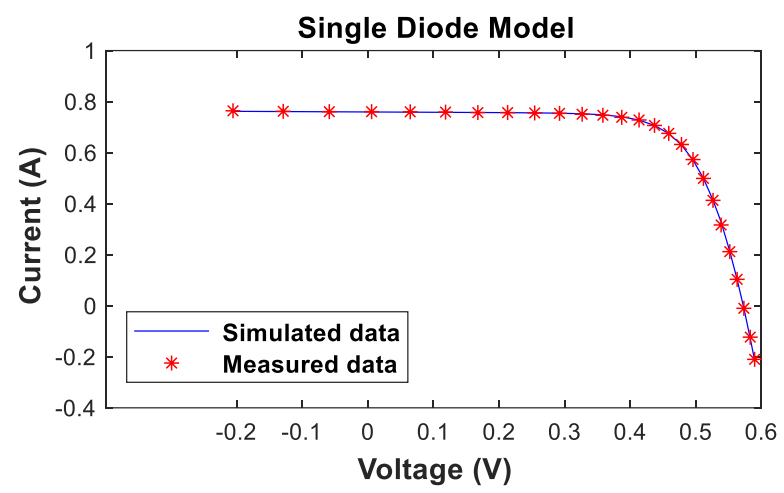

(i)

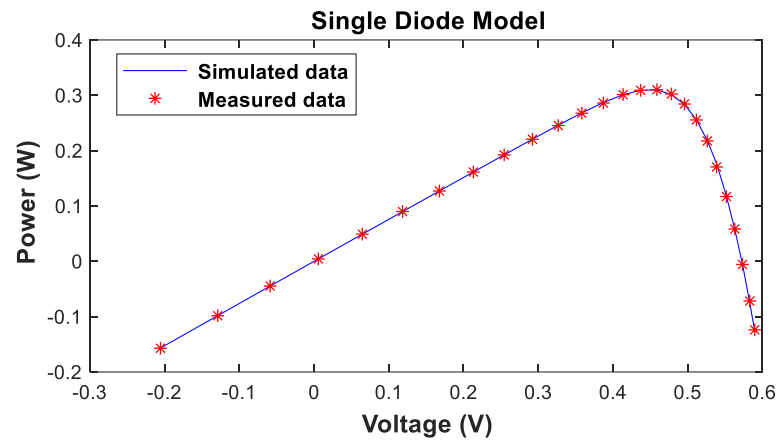

(ii)

Figure 4. Experimental and estimated data comparison using GWO for single diode model (i) characteristics curve of I-V (ii) characteristics curve of P-V.

Table 3. Comparison of GWO with other parameter estimation methods for SDM.

\begin{tabular}{|c|c|c|c|c|c|c|}
\hline Algorithms & $\mathbf{I}_{p}(\mathbf{A})$ & $\mathbf{I}_{\boldsymbol{s} \boldsymbol{d}}(\boldsymbol{\mu} \mathbf{A})$ & $\mathbf{R}_{\mathbf{s}}(\mathbf{\Omega})$ & $\mathbf{R}_{\text {sh }}(\boldsymbol{\Omega})$ & $\mathbf{a}$ & $\mathbf{R M S E}$ \\
\hline GSA & 0.7575 & 0.5 & 0.0396 & 58.71143 & 1.5507 & $1.16 \mathrm{E}-03$ \\
\hline PSOGSA & 0.7677 & 0.01 & 0.0522 & 18.45874 & 1.218 & $1.26 \mathrm{E}-02$ \\
\hline SCA & 0.6493 & 0.454 & 0.0235 & 44.07847 & 1.5863 & $2.08 \mathrm{E}-03$ \\
\hline CSO & 0.76065 & 0.41 & 0.035318 & 60.01702 & 1.5279 & $9.73 \mathrm{E}-04$ \\
\hline CA & 0.76017 & 0.6609 & 0.0322 & 80.8217 & 1.5179 & $1.45 \mathrm{E}-03$ \\
\hline GWO & 0.7597 & 0.499 & 0.0342 & 83.0131 & 1.5483 & $9.41 \mathrm{E}-04$ \\
\hline
\end{tabular}


International Journal of Mathematical, Engineering and Management Sciences

Vol. 6, No. 3, 911-931, 2021

https://doi.org/10.33889/IJMEMS.2021.6.3.054
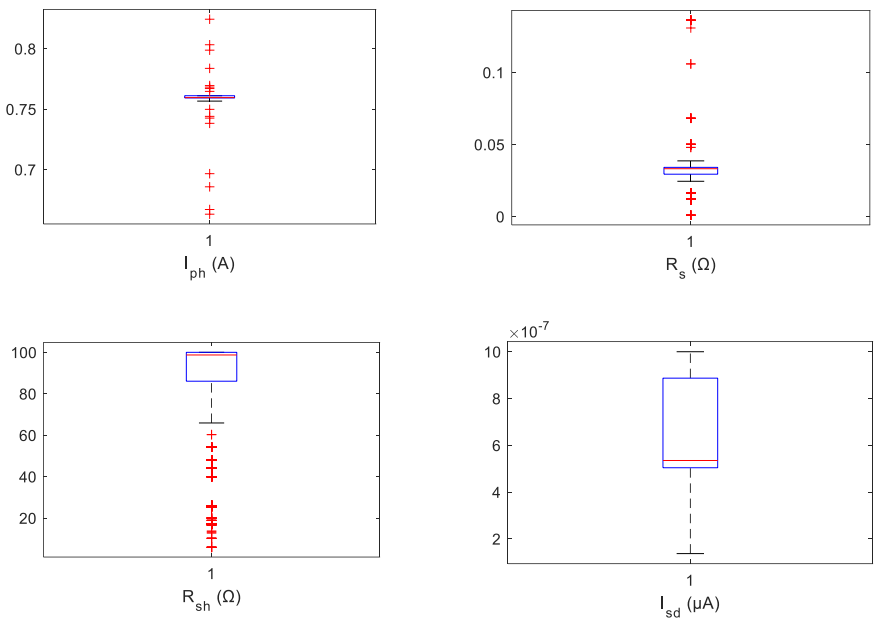

Figure 5. Boxplot of single diode parameters $\left(\mathrm{I}_{\mathrm{p}}, \mathrm{R}_{\mathrm{s}}, \mathrm{R}_{\mathrm{sh}}, \mathrm{I}_{\mathrm{sd}}\right)$ using $\mathrm{GWO}$ algorithm.

Table 4. Value of absolute error and estimated current obtained by GWO for SDM.

\begin{tabular}{|c|c|c|c|c|}
\hline Observations & $\mathbf{V}_{\mathrm{L}}(\mathbf{V})$ & $\mathbf{I}_{\mathrm{L}}(\mathbf{A})$ & $\mathbf{I}_{\mathrm{L}}$ estimated (A) & IAE \\
\hline (I) & 0.2057 & 0.764 & 0.7619 & 0.0020 \\
\hline (II) & 0.1291 & 0.762 & 0.7609 & 0.0010 \\
\hline (III) & 0.0588 & 0.7605 & 0.7601 & 0.0003 \\
\hline (IV) & 0.0057 & 0.7605 & 0.7593 & 0.0011 \\
\hline$(\mathrm{V})$ & 0.0646 & 0.76 & 0.7586 & 0.0013 \\
\hline (VI) & 0.1185 & 0.759 & 0.7579 & 0.0010 \\
\hline (VII) & 0.1678 & 0.757 & 0.7573 & 0.0003 \\
\hline (VIII) & 0.2132 & 0.757 & 0.7566 & 0.0003 \\
\hline (IX) & 0.2545 & 0.7555 & 0.7558 & 0.0003 \\
\hline$(\mathrm{X})$ & 0.2924 & 0.754 & 0.7545 & 0.0005 \\
\hline (XI) & 0.3269 & 0.7505 & 0.7523 & 0.0018 \\
\hline (XII) & 0.3585 & 0.7465 & 0.7481 & 0.0016 \\
\hline (XIII) & 0.3873 & 0.7385 & 0.7406 & 0.0021 \\
\hline (XIV) & 0.4137 & 0.728 & 0.7275 & 0.0004 \\
\hline$(\mathrm{XV})$ & 0.4373 & 0.7065 & 0.7066 & 0.0001 \\
\hline$(\mathrm{XVI})$ & 0.459 & 0.6755 & 0.6746 & 0.0008 \\
\hline (XVII) & 0.4784 & 0.632 & 0.6299 & 0.0020 \\
\hline (XVIII) & 0.496 & 0.573 & 0.5712 & 0.0017 \\
\hline (XIX) & 0.5119 & 0.499 & 0.4993 & 0.0003 \\
\hline$(\mathrm{XX})$ & 0.5265 & 0.413 & 0.4139 & 0.0009 \\
\hline$(\mathrm{XXI})$ & 0.5398 & 0.3165 & 0.3279 & 0.0014 \\
\hline (XXII) & 0.5521 & 0.212 & 0.2130 & 0.0010 \\
\hline (XXIII) & 0.5633 & 0.1035 & 0.1026 & 0.0008 \\
\hline (XXIV) & 0.5736 & -0.01 & 0.0096 & 0.0003 \\
\hline$(\mathrm{XXV})$ & 0.5833 & -0.123 & 0.1284 & 0.0054 \\
\hline$(\mathrm{XXVI})$ & 0.59 & -0.21 & 0.2137 & 0.0037 \\
\hline Sum of IAE & & & & 0.0436 \\
\hline
\end{tabular}


International Journal of Mathematical, Engineering and Management Sciences

Vol. 6, No. 3, 911-931, 2021

https://doi.org/10.33889/IJMEMS.2021.6.3.054

The characteristics curve of current-voltage and power voltage for single diode model is redrawn based on best optimized parameters obtained by implementing the GWO algorithm and clearly depicted in Figure 4. It is depicted in Figure 1, that calculated data obtained by the GWO is very effectively in coincidence with the experimental data set, under STC (i.e., $1000 \mathrm{w} / \mathrm{m}^{2}$ and $33^{\circ} \mathrm{C}$ ), all over the voltage range. Table 4 represents the individual absolute error (IAE) in between calculated and experimental data set. Every determined value of IAE in Table 4 is less than 5.4244E-03 which indicates that the parameters optimized by the GWO are very precise. The distribution of values for all optimized parameters is shown with the help of box plot in Figure 5 . Boxplot is a systematic way to represent the distribution of the data based on five parameters median, first quartile $(\mathrm{Q} 1)$ minimum, second quartile $(\mathrm{Q} 2)$ and maximum. The boxplot of $\mathrm{I}_{\mathrm{ph}}$ parameter, the second quartile $(\mathrm{Q} 2)$ shows that $75 \%$ of data is $0.7597 \mathrm{~A}$. In the case of $\mathrm{R}_{\mathrm{s}}$ parameter, the second quartile $(\mathrm{Q} 2)$ shows that $75 \%$ of data is $0.0342 \Omega$, similarly for $\mathrm{R}_{\text {sh }}$ the second quartile (Q2) shows that $75 \%$ of data is equal to $83.01 \Omega$. While for $I_{\text {sd }}$ parameter the second quartile (Q2) depicts that $75 \%$ of data is $0.499 \mu \mathrm{A}$. This distribution of optimized parameters clearly shows the effectiveness of GWO algorithm in terms of average accuracy.

\subsection{Simulation Results for DDM}

In the case of DDM, there are basically seven parameters $\left(I_{p}, I_{s d}, I_{s d 1}, a_{1}, a_{2}, R_{s}, R_{s h}\right)$ which are required to be optimized. The values of optimized parameters and minimum of RMSE are presented in Table 5, for the comparison. GWO also produces the best value in terms of RMSE (1.24501E03) as compared to other algorithms. The characteristics curve in terms of current-voltage and power-voltage for double diode model is redrawn based on best optimized parameters obtained by implementing the GWO algorithm and clearly depicted in Figure 6. The values of individual absolute error are depicted in Table 6. From Figure 6, it can be clearly projected that the estimated data based on optimized parameters is in highly coincidence with the experimental data set. From Table 6, it can be easily analyzed that all the values of IAE are less than 1.2880E-02, which demonstrates the accuracy of optimized parameters produced by GWO. The distribution of values for all optimized parameters is shown with the help of box plot in Figure 7. Boxplot is a systematic way to represent the distribution of the data based on five parameters median, first quartile (Q1) minimum, second quartile $(\mathrm{Q} 2)$ and maximum. The boxplot of Iph parameter, the second quartile (Q2) shows that $75 \%$ of data is $0.7601 \mathrm{~A}$. In the case of $R_{s}$ parameter, the second quartile (Q2) shows that $75 \%$ of data is $0.033 \Omega$, similarly for $R_{s h}$ the second quartile $(\mathrm{Q} 2)$ shows that $75 \%$ of data is equal to $55.31 \Omega$. While for $I_{s d l}$ parameter the second quartile $(\mathrm{Q} 2)$ depicts that $75 \%$ of data is $0.4356 \mu \mathrm{A}$ and for $I_{s d 2}$ parameter the second quartile (Q2) depicts that $75 \%$ of data is $0.352 \mu \mathrm{A}$. This distribution of optimized parameters clearly shows the effectiveness of GWO algorithm in terms of average accuracy.

Table 5. Comparison of GWO with other parameter estimation methods for DD.

\begin{tabular}{|c|c|c|c|c|c|c|c|c|}
\hline Algorithms & $\mathbf{I}_{\mathbf{p}}(\mathbf{A})$ & $\mathbf{I}_{\text {sd1 }}(\boldsymbol{\mu} \mathbf{A})$ & $\mathbf{I}_{\mathbf{s d} 2}(\boldsymbol{\mu} \mathbf{A})$ & $\mathbf{R}_{\mathbf{s}}(\boldsymbol{\Omega})$ & $\mathbf{R}_{\text {sh }}(\boldsymbol{\Omega})$ & $\mathbf{a}_{\mathbf{1}}$ & $\mathbf{a}_{\mathbf{2}}$ & $\mathbf{R M S E}$ \\
\hline GSA & 0.764 & 0.05 & 0.01 & 0.0345 & 37.78 & 1.9943 & 1.5492 & $2.03 \mathrm{E}-02$ \\
\hline PSOGSA & 0.7611 & 0.432 & 0.01 & 0.0347 & 61.72 & 1.9999 & 1.5489 & $1.48 \mathrm{E}-01$ \\
\hline SCA & 0.7622 & 0.126 & 0.0125 & 0.0595 & 52.4903 & 2 & 1.2197 & $3.18 \mathrm{E}-02$ \\
\hline CSO & 0.7676 & 0.0216 & 0.0947 & 0.0335 & 54.9501 & 1.4606 & 1.8363 & $1.73 \mathrm{E}-03$ \\
\hline CA & 0.7583 & 0.0466 & 0.001 & 0.0551 & 52.567 & 1.8312 & 1.3339 & $3.10 \mathrm{E}-03$ \\
\hline GWO & 0.7601 & 0.4356 & 0.352 & 0.0333 & 55.3129 & 2 & 1.512 & $1.245 \mathrm{E}-03$ \\
\hline
\end{tabular}


International Journal of Mathematical, Engineering and Management Sciences

Vol. 6, No. 3, 911-931, 2021

https://doi.org/10.33889/IJMEMS.2021.6.3.054

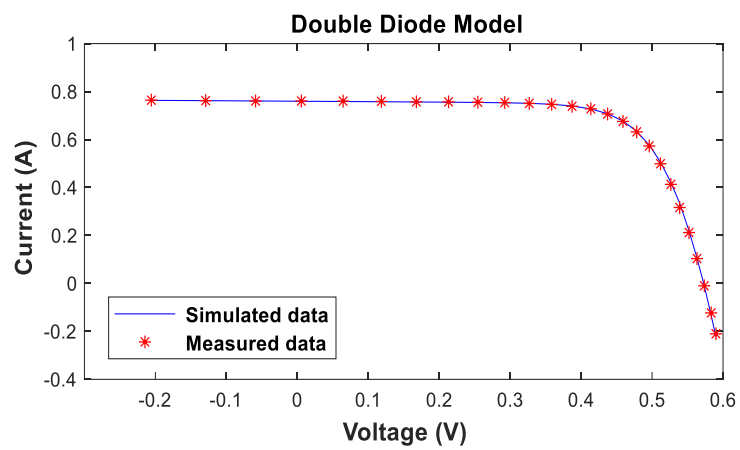

(i)

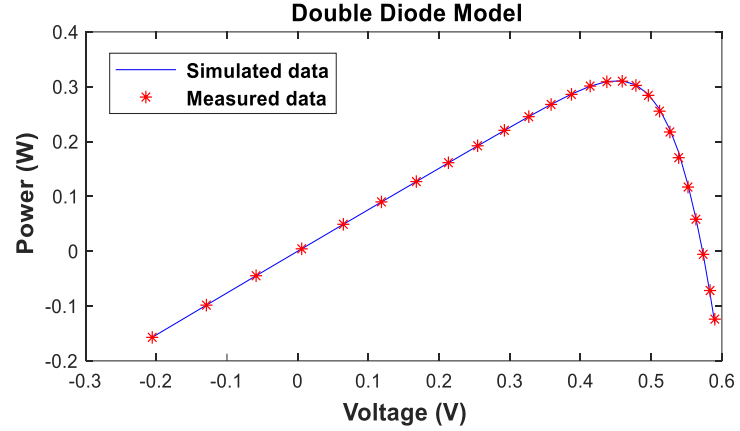

(ii)

Figure 6. Experimental and estimated data comparison using GWO for double diode model (i) characteristics curve of I-V (ii) characteristics curve of $\mathrm{P}-\mathrm{V}$.
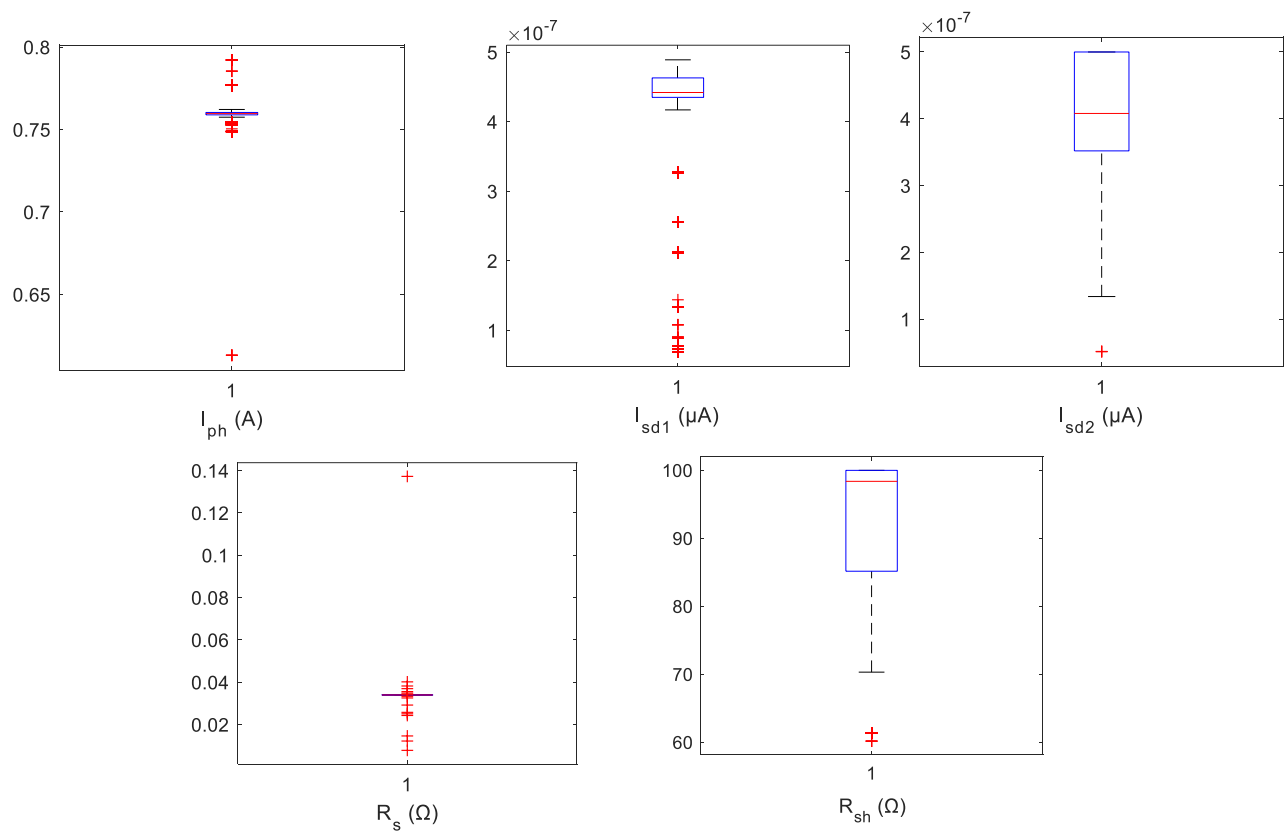

Figure 7. Boxplot of double diode parameters $\left(I_{p h}, I_{s d 1}, I_{s d 2}, R_{s}, R_{s h}\right)$ using GWO algorithm. 
International Journal of Mathematical, Engineering and Management Sciences

Vol. 6, No. 3, 911-931, 2021

https://doi.org/10.33889/IJMEMS.2021.6.3.054

Table 6. Value of absolute error and estimated current obtained by GWO for DDM.

\begin{tabular}{|c|c|c|c|c|}
\hline Observations & $V_{L}(V)$ & $\mathbf{I}_{\mathrm{L}}(\mathrm{A})$ & $\mathbf{I}_{\mathrm{L}}$ estimated (A) & IAE \\
\hline (I) & 0.2057 & 0.764 & 0.7633 & 0.0006 \\
\hline (II) & 0.1291 & 0.762 & 0.7619 & 0.00002 \\
\hline (III) & 0.0588 & 0.7605 & 0.7607 & 0.0002 \\
\hline (IV) & 0.0057 & 0.7605 & 0.7595 & 0.0009 \\
\hline (V) & 0.0646 & 0.76 & 0.7584 & 0.0015 \\
\hline (VI) & 0.1185 & 0.759 & 0.7574 & 0.0015 \\
\hline (VII) & 0.1678 & 0.757 & 0.7565 & 0.0004 \\
\hline (VIII) & 0.2132 & 0.757 & 0.7556 & 0.0013 \\
\hline (IX) & 0.2545 & 0.7555 & 0.7545 & 0.0009 \\
\hline$(\mathrm{X})$ & 0.2924 & 0.754 & 0.7531 & 0.0008 \\
\hline (XI) & 0.3269 & 0.7505 & 0.7509 & 0.0004 \\
\hline (XII) & 0.3585 & 0.7465 & 0.7469 & 0.0004 \\
\hline (XIII) & 0.3873 & 0.7385 & 0.7398 & 0.0013 \\
\hline (XIV) & 0.4137 & 0.728 & 0.7274 & 0.0005 \\
\hline$(\mathrm{XV})$ & 0.4373 & 0.7065 & 0.7076 & 0.0011 \\
\hline$(\mathrm{XVI})$ & 0.459 & 0.6755 & 0.6770 & 0.0015 \\
\hline (XVII) & 0.4784 & 0.632 & 0.6339 & 0.0019 \\
\hline (XVIII) & 0.496 & 0.573 & 0.5768 & 0.0038 \\
\hline$(\mathrm{XIX})$ & 0.5119 & 0.499 & 0.5060 & 0.0070 \\
\hline$(\mathrm{XX})$ & 0.5265 & 0.413 & 0.4211 & 0.0081 \\
\hline (XXI) & 0.5398 & 0.3165 & 0.3347 & 0.0182 \\
\hline (XXII) & 0.5521 & 0.212 & 0.2185 & 0.0065 \\
\hline (XXIII) & 0.5633 & 0.1035 & 0.1058 & 0.0023 \\
\hline (XXIV) & 0.5736 & -0.01 & 0.0100 & 0.0010 \\
\hline$(\mathrm{XXV})$ & 0.5833 & -0.123 & 0.1334 & 0.0104 \\
\hline$(\mathrm{XXVI})$ & 0.59 & -0.21 & 0.2228 & 0.0128 \\
\hline Sum of IAE & & & & 0.0854 \\
\hline
\end{tabular}

\subsection{Statistical Evaluation with Previous Implemented Algorithms}

This section presents statistical evaluation based on mean, minimum, maximum, and standard deviation of RMSE for all previous implemented methods, and a comparison with respect to precision and consistency of the distinct algorithms in total of thirty runs and depicted in Table 7. The mean of RMSE is calculated to evaluate the precision of algorithms and standard deviation is calculated to evaluate the consistency of the parameter estimation methods. 
International Journal of Mathematical, Engineering and Management Sciences

Vol. 6, No. 3, 911-931, 2021

https://doi.org/10.33889/IJMEMS.2021.6.3.054

Table 7. Statistical evaluation of distinct algorithms implemented in previous investigation for both models.

\begin{tabular}{|c|c|c|c|c|c|}
\hline \multirow{4}{*}{ Model } & Algorithm & \multicolumn{5}{|c|}{ RMSE } \\
\cline { 2 - 6 } & & Minimum & Mean & Maximum & SD \\
\hline \multirow{4}{*}{ SDM } & PS & $1.494 \mathrm{E}-02$ & - & - & - \\
\cline { 2 - 6 } & SA & $1.90 \mathrm{E}-02$ & - & - & - \\
\cline { 2 - 6 } & HS & $9.95 \mathrm{E}-04$ & $1.2653 \mathrm{E}-03$ & $1.4174 \mathrm{E}-03$ & $1.1981 \mathrm{E}-04$ \\
\cline { 2 - 6 } & PSO & $1.39 \mathrm{E}-03$ & - & - & - \\
\cline { 2 - 6 } & GA & $1.87 \mathrm{E}-02$ & - & - & $1.405 \mathrm{E}-05$ \\
\cline { 2 - 6 } & GWO & $9.4094 \mathrm{E}-04$ & $1.04412 \mathrm{E}-03$ & $1.3536 \mathrm{E}-03$ & - \\
\hline \multirow{5}{*}{ DDM } & PS & $1.518 \mathrm{E}-02$ & - & - & $1.4625 \mathrm{E}-04$ \\
\cline { 2 - 6 } & SA & $1.664 \mathrm{E}-02$ & - & - & - \\
\cline { 2 - 6 } & HS & $1.2600 \mathrm{E}-03$ & $1.0074 \mathrm{E}-03$ & $1.35262 \mathrm{E}-03$ & - \\
\cline { 2 - 6 } & PSO & $1.6600 \mathrm{E}-02$ & - & - & $1.0957 \mathrm{E}-04$ \\
\hline
\end{tabular}

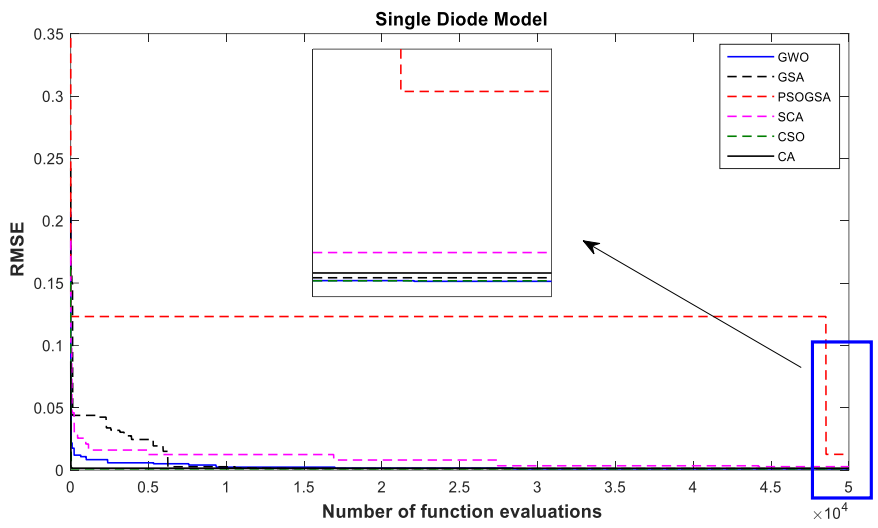

(a)

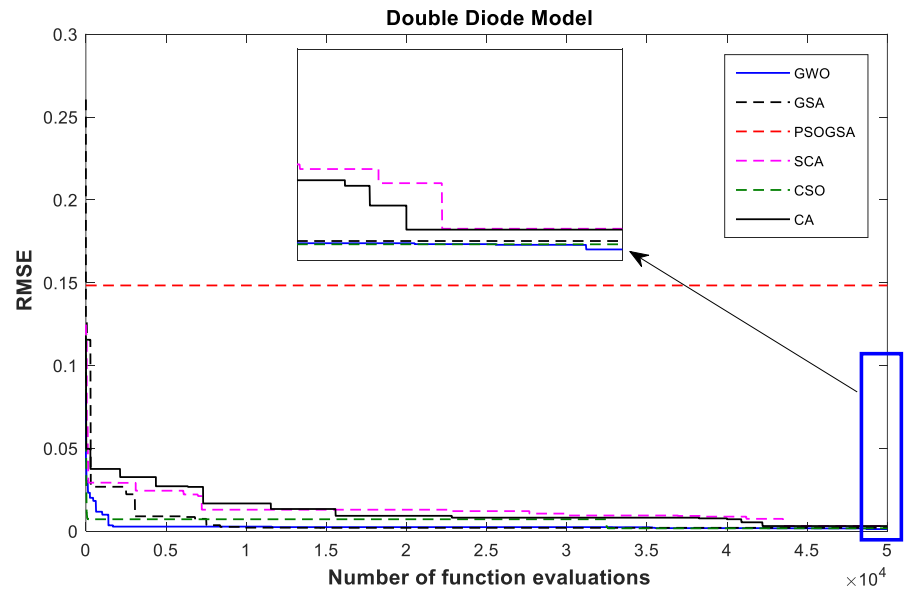

(b)

Figure 8. Convergence curves (a) for different algorithms for single diode model (b) for different algorithms for double diode model. 
From Table 7, GWO provides the best result in terms of all four indicators: minimum, standard deviation, maximum and mean as compared to other algorithms. HS attains the second-best value in terms of minimum RMSE followed by PSO, PS, SA and GA respectively. In the case of DDM, GWO provides best value in terms of minimum and standard deviation of RMSE while HS gets best value in terms of mean and maximum and it can be easily predicted that HS is good in terms of reliability as compared to GWO. The convergence curves of GWO for SDM and DDM is presented in Figure 8. In the case of SDM, GWO converges to optimal value of estimated parameters at RMSE equivalent to 9.4094E- 04 in 48,920 evaluations. For DDM, GWO converges to optimal value of unknown parameters at RMSE of 1.2450E- 03 at 49,210 evaluations.

Based on the above discussed comparisons, it can be determined that the GWO algorithm is very good with respect to reliability and accuracy of solution to estimate the model parameters of distinct types (SDM and DDM) of solar PV models.

\subsection{Analysis of Electrical Performance}

In this subsection the proposed GWO technique is compared with the algorithms PS, SA, HS, PSO and GA based on mainly four electrical performance parameters: maximum current $\left(\mathrm{I}_{\mathrm{m}}\right)$, voltage $\left(\mathrm{V}_{\mathrm{m}}\right)$, power $\left(\mathrm{P}_{\mathrm{m}}\right)$ and fill factor $(\mathrm{FF})$ for the SDM and DDM of PV cell. The error in maximum current and power is represented by $\Delta \mathrm{I}_{\mathrm{m}}$ and $\Delta \mathrm{P}_{\mathrm{m}}$.

Table 8. Performance comparison of electrical parameters.

\begin{tabular}{|c|c|c|c|c|c|c|c|c|c|c|}
\hline Algorithm & \multicolumn{3}{|c|}{ Single Diode Model } & & & \multicolumn{3}{c|}{ Double Diode Model } & & \\
\hline & $\mathbf{I}_{\mathbf{m}}(\mathbf{A})$ & $\mathbf{V}_{\mathbf{m}}(\mathbf{V})$ & $\mathbf{P}_{\mathbf{m}}(\mathbf{W})$ & $\Delta \mathbf{I}_{\mathbf{m}}(\mathbf{A})$ & $\Delta \mathbf{P}_{\mathbf{m}}(\mathbf{W})$ & $\mathbf{I}_{\mathbf{m}}(\mathbf{A})$ & $\mathbf{V}_{\mathbf{m}}(\mathbf{V})$ & $\mathbf{P}_{\mathbf{m}}(\mathbf{W})$ & $\boldsymbol{\Delta} \mathbf{I}_{\mathbf{m}}(\mathbf{A})$ & $\Delta \mathbf{P}_{\mathbf{m}}(\mathbf{W})$ \\
\hline PSO & 65.97 & 45.9 & 30.28 & 4.68 & 0.73 & 65.7 & 45.9 & 30.16 & 4.95 & 0.85 \\
\hline HS & 66.02 & 45.9 & 30.3 & 4.63 & 0.71 & 65.87 & 45.9 & 30.24 & 4.78 & 0.77 \\
\hline PS & 65.15 & 45.9 & 29.9 & 5.5 & 1.11 & 38.8 & 45.9 & 16.05 & 31.85 & 14.96 \\
\hline SA & 65.29 & 45.9 & 29.97 & 5.36 & 1.04 & 65.37 & 45.9 & 30 & 5.28 & 1.01 \\
\hline GA & 65.3 & 45.9 & 29.97 & 5.35 & 1.04 & 30.67 & 45.9 & 26.12 & 39.98 & 4.89 \\
\hline GWO & 67.46 & 45.9 & 30.96 & 3.19 & 0.05 & 67.66 & 45.9 & 30.97 & 2.99 & 0.04 \\
\hline
\end{tabular}

The estimated values of single diode parameters are considered to obtain the values of performance parameters $\left(I_{m}, V_{m}, P_{m}\right)$ for all the optimization methods. From Table 8 and Figure 9, it is observed that the best values of $\mathrm{I}_{\mathrm{m}}, \mathrm{V}_{\mathrm{m}}$ and $\mathrm{P}_{\mathrm{m}}$ (in percentage) are obtained by GWO algorithm as $67.46 \mathrm{~A}$, $45.9 \mathrm{~V}$ and $30.96 \mathrm{~W}$ respectively. The second-best values are obtained by HS while GA gets the lowest values. GWO also gets best value of FF as $68.69 \%$ which is $1.46 \%$ higher than HS and followed by PSO, GA, SA and PS as shown in Figure 10. 
International Journal of Mathematical, Engineering and Management Sciences

Vol. 6, No. 3, 911-931, 2021

https://doi.org/10.33889/IJMEMS.2021.6.3.054

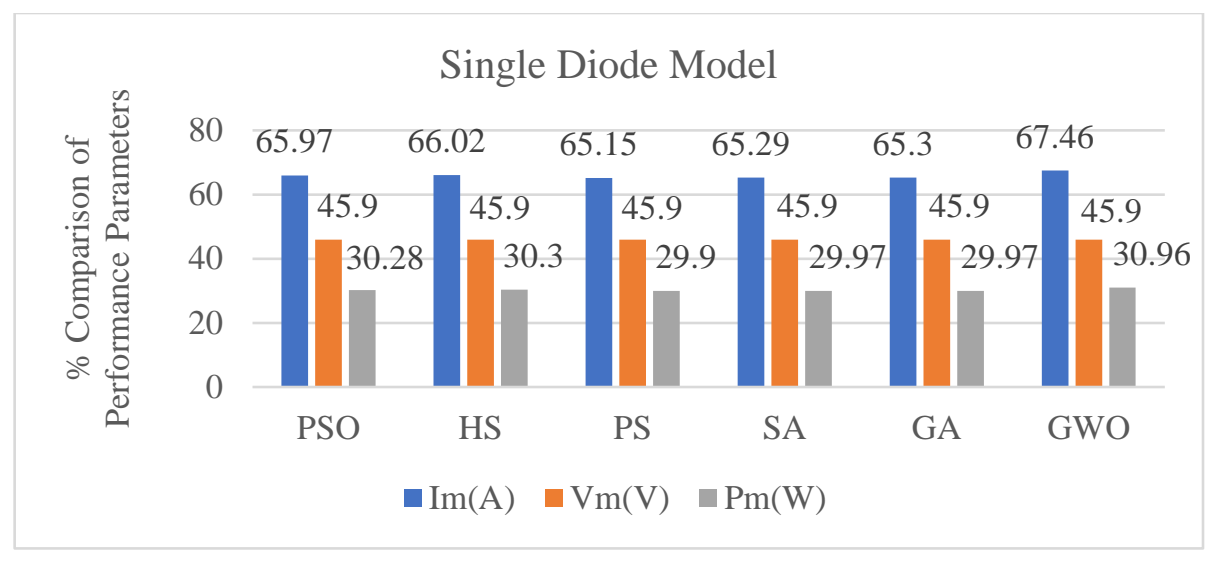

Figure 9. Comparison of performance parameters $\left(I_{m}, V_{m}, P_{m}\right)$ for single diode model.

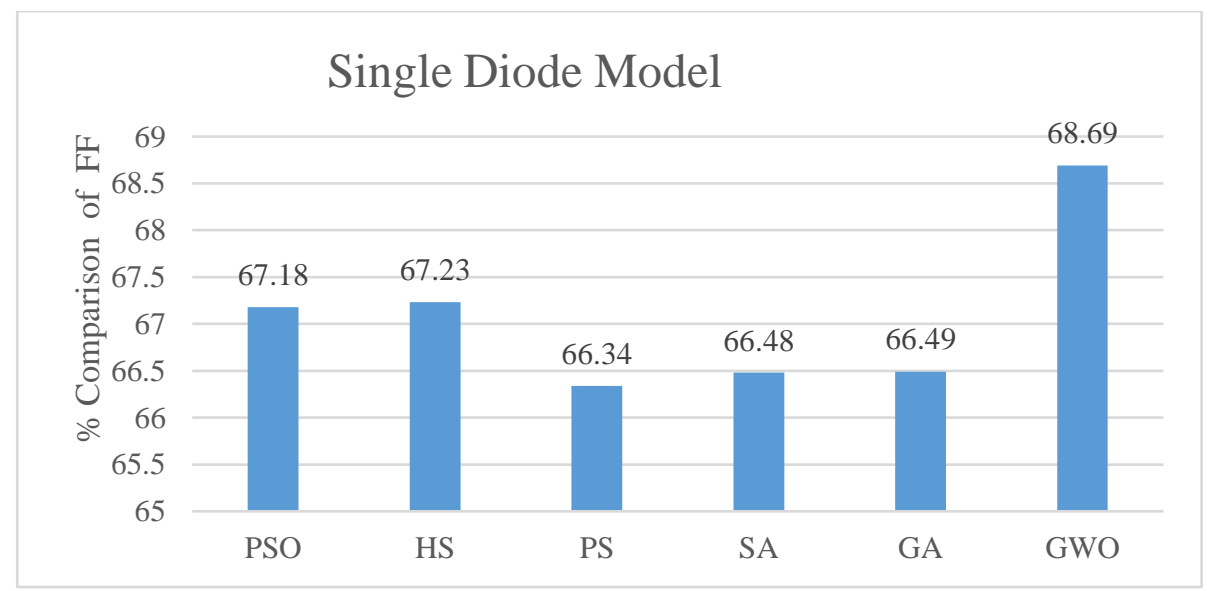

Figure 10. Comparison of fill-factor for single diode model.

GWO provides the highest values of electrical performance parameters for DDM of PV cell as shown in the Table 8. It is noted that the highest values of $\mathrm{I}_{\mathrm{m}}, \mathrm{V}_{\mathrm{m}}$ and $\mathrm{P}_{\mathrm{m}}$ as $67.66 \mathrm{~A}, 45.9 \mathrm{~V}$ and $31.05 \mathrm{~W}$ are obtained by the GWO algorithm as depicted in Figure 11. In addition, the other algorithms as HS achieve the second largest value while GA achieves the smallest value of performance parameters. The maximum FF value of $68.90 \%$ is achieved by GWO, which is $1.83 \%$ higher than HS, followed by PSO, GA, SA and PS as shown in Figure 12. 
International Journal of Mathematical, Engineering and Management Sciences

Vol. 6, No. 3, 911-931, 2021

https://doi.org/10.33889/IJMEMS.2021.6.3.054

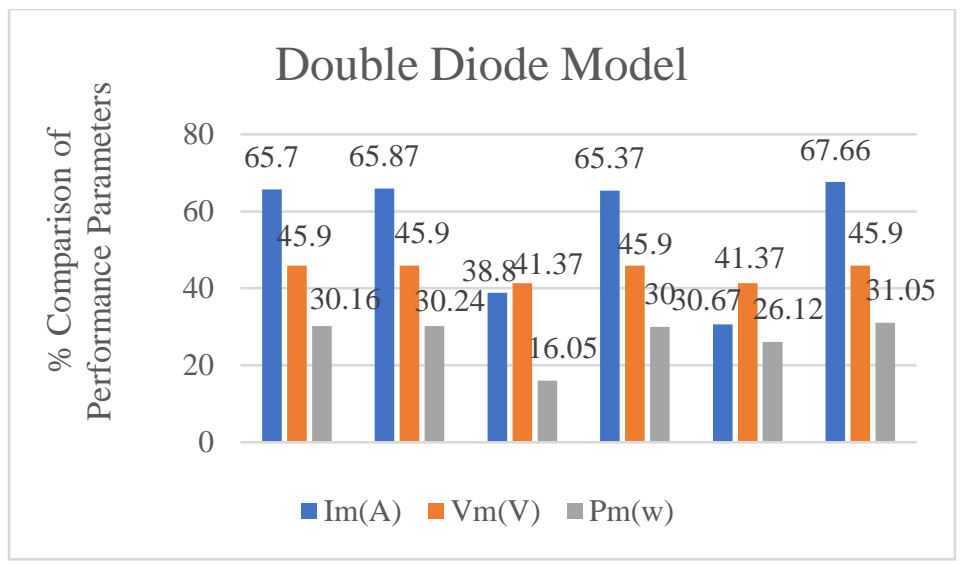

Figure 11. Comparison of performance parameters $\left(I_{m}, V_{m}, P_{m}\right)$ for double diode model.

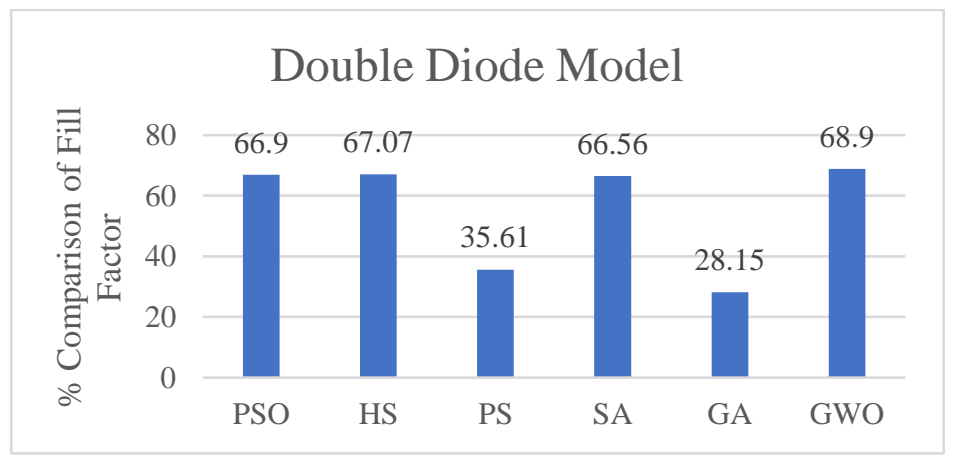

Figure 12. Comparison of fill-factor for double diode model.

\section{Conclusions}

In this article, the grey wolf optimization (GWO) algorithm has been implemented to estimate the parameters of SDM and DDM respectively. The salient points of the study are given as follows,

- GWO is compared with five pre-existing and well-established algorithms in the literature, they are PS, SA, HS, PSO and GA.

- All the parameters i.e., five and seven parameters are extracted for single and double diode model by using GWO algorithm and RMSE value is calculated as well as compared with other algorithms.

- Simulation results clearly indicates that the best values of estimated parameters are obtained by GWO, and RMSE is 9.4094E-04 and 1.2450E- 03 in the case of single and double diode respectively.

- Furthermore, estimated parameters obtained by GWO are compared with other algorithms in terms of electrical performance parameters such as $\mathrm{I}_{\mathrm{m}}, \mathrm{V}_{\mathrm{m}}, \mathrm{P}_{\mathrm{m}}$ and FF.

- In the case of SDM, the best values of $\mathrm{I}_{\mathrm{m}}, \mathrm{V}_{\mathrm{m}}$ and $\mathrm{P}_{\mathrm{m}}$ are obtained by GWO algorithm as 67.46 A, $45.9 \mathrm{~V}$ and $30.96 \mathrm{~W}$ respectively. Moreover, GWO provided the improved FF of $1.46 \%$. 
International Journal of Mathematical, Engineering and Management Sciences

Vol. 6, No. 3, 911-931, 2021

https://doi.org/10.33889/IJMEMS.2021.6.3.054

- The highest values of $\mathrm{I}_{\mathrm{m}}, \mathrm{V}_{\mathrm{m}}$ and $\mathrm{P}_{\mathrm{m}}$ are achieved by the GWO algorithm as $67.66 \mathrm{~A}, 45.9 \mathrm{~V}$ and $31.05 \mathrm{~W}$ accordingly, the case of DDM. In addition to this, GWO also produced the improved FF of $1.83 \%$.

- Maximum error of the estimations lays under 3\% whereas average error is under $0.2-0.4 \%$, which is much better than for another methods of parameters estimation.

From above discussion, it is concluded that GWO is an efficient and robust technique to estimate the unknown optimized parameters of solar PV model.

\section{Conflict of Interest}

The authors confirm that there is no conflict of interest to declare for this publication.

\section{Acknowledgements}

The authors would like to express their sincere thanks to the editor and anonymous reviews for their time and valuable suggestions.

\section{References}

Alam, D.F., Yousri, D.A., \& Eteiba, M.B. (2015). Flower pollination algorithm based solar PV parameter estimation. Energy Conversion and Management, 101, 410-422.

AlHajri, M.F., El-Naggar, K.M., AlRashidi, M.R., \& Al-Othman, A.K. (2012). Optimal extraction of solar cell parameters using pattern search. Renewable Energy, 44, 238-245.

AlRashidi, M.R., AlHajri, M.F., El-Naggar, K.M., \& Al-Othman, A.K. (2011). A new estimation approach for determining the I-V characteristics of solar cells. Solar Energy, 85(7), 1543-1550.

Armghan, H., Ahmad, I., Armghan, A., Khan, S., \& Arsalan, M. (2018). Backstepping based non-linear control for maximum power point tracking in photovoltaic system. Solar Energy, 159, 134-141.

Aryanpur, V., Atabaki, M.S., Marzband, M., Siano, P., \& Ghayoumi, K. (2019). An overview of energy planning in Iran and transition pathways towards sustainable electricity supply sector. Renewable and Sustainable Energy Reviews, 112, 58-74.

Askarzadeh, A., \& Rezazadeh, A. (2012). Parameter identification for solar cell models using harmony search-based algorithms. Solar Energy, 86(11), 3241-3249.

Askarzadeh, A., \& Rezazadeh, A. (2013a). Artificial bee swarm optimization algorithm for parameters identification of solar cell models. Applied Energy, 102, 943-949.

Askarzadeh, A., \& Rezazadeh, A. (2013b). Extraction of maximum power point in solar cells using bird mating optimizer-based parameters identification approach. Solar Energy, 90, 123-133.

Batzelis, E.I., \& Papathanassiou, S.A. (2015). A method for the analytical extraction of the single-diode PV model parameters. IEEE Transactions on Sustainable Energy, 7(2), 504-512.

Beigi, A.M., \& Maroosi, A. (2018). Parameter identification for solar cells and module using a hybrid firefly and pattern search algorithms. Solar Energy, 171, 435-446.

Brano, V.L., \& Ciulla, G. (2013). An efficient analytical approach for obtaining a five parameters model of photovoltaic modules using only reference data. Applied Energy, 111, 894-903.

Chegaar, M., Ouennoughi, Z., \& Hoffmann, A. (2001). A new method for evaluating illuminated solar cell parameters. Solid-State Electronics, 45(2), 293-296.

Chen, Y., Chen, Z., Wu, L., Long, C., Lin, P., \& Cheng, S. (2019). Parameter extraction of PV models using an enhanced shuffled complex evolution algorithm improved by opposition-based learning. Energy Procedia, 158, 991-997. 
International Journal of Mathematical, Engineering and Management Sciences

Vol. 6, No. 3, 911-931, 2021

https://doi.org/10.33889/IJMEMS.2021.6.3.054

Chen, Z., Wu, L., Lin, P., Wu, Y., \& Cheng, S. (2016). Parameters identification of photovoltaic models using hybrid adaptive Nelder-Mead simplex algorithm based on eagle strategy. Applied Energy, 182, 4757.

Chin, V.J., Salam, Z., \& Ishaque, K. (2015). Cell modelling and model parameters estimation techniques for photovoltaic simulator application: a review. Applied Energy, 154, 500-519.

Coello, C.A.C., Lamont, G.B., \& Van Veldhuizen, D.A. (2007). Evolutionary algorithms for solving multiobjective problems (Vol. 5, pp. 79-104). Springer, New York.

Easwarakhanthan, T., Bottin, J., Bouhouch, I., \& Boutrit, C. (1986). Nonlinear minimization algorithm for determining the solar cell parameters with microcomputers. International Journal of Solar Energy, 4(1), $1-12$.

Elaziz, M.A., \& Oliva, D. (2018). Parameter estimation of solar cells diode models by an improved opposition-based whale optimization algorithm. Energy Conversion and Management, 171, 1843-1859.

El-Naggar, K.M., AlRashidi, M.R., AlHajri, M.F., \& Al-Othman, A.K. (2012). Simulated annealing algorithm for photovoltaic parameters identification. Solar Energy, 86(1), 266-274.

Esram, T., \& Chapman, P.L. (2007). Comparison of photovoltaic array maximum power point tracking techniques. IEEE Transactions on Energy Conversion, 22(2), 439-449.

Gao, X., Cui, Y., Hu, J., Xu, G., \& Yu, Y. (2016). Lambert W-function based exact representation for double diode model of solar cells: comparison on fitness and parameter extraction. Energy Conversion and Management, 127, 443-460.

Gielen, D., Boshell, F., Saygin, D., Bazilian, M.D., Wagner, N., \& Gorini, R. (2019). The role of renewable energy in the global energy transformation. Energy Strategy Reviews, 24, 38-50.

Gomes, R.C.M., Vitorino, M.A., de Rossiter Corrêa, M.B., Fernandes, D.A., \& Wang, R. (2016). Shuffled complex evolution on photovoltaic parameter extraction: a comparative analysis. IEEE Transactions on Sustainable Energy, 8(2), 805-815.

Gong, W., \& Cai, Z. (2013). Parameter extraction of solar cell models using repaired adaptive differential evolution. Solar Energy, 94, 209-220.

Ishaque, K., Salam, Z., Mekhilef, S., \& Shamsudin, A. (2012). Parameter extraction of solar photovoltaic modules using penalty-based differential evolution. Applied Energy, 99, 297-308.

Ismail, M.S., Moghavvemi, M., \& Mahlia, T.M.I. (2013). Characterization of PV panel and global optimization of its model parameters using genetic algorithm. Energy Conversion and Management, 73, 10-25.

Jayapriya, J., \& Arock, M. (2015). A parallel GWO technique for aligning multiple molecular sequences. Paper presented at the 2015 International Conference on Advances in Computing, Communications and Informatics (ICACCI), (pp. 210-215). IEEE. Kochi, India.

Jervase, J.A., Bourdoucen, H., \& Al-Lawati, A. (2001). Solar cell parameter extraction using genetic algorithms. Measurement Science and Technology, 12(11), 1922.

Jordehi, A.R. (2016). Parameter estimation of solar photovoltaic (PV) cells: a review. Renewable and Sustainable Energy Reviews, 61, 354-371.

Khan, F., Baek, S.H., \& Kim, J.H. (2016). Wide range temperature dependence of analytical photovoltaic cell parameters for silicon solar cells under high illumination conditions. Applied Energy, 183, 715-724.

Khanna, V., Das, B.K., Bisht, D., \& Singh, P.K. (2015). A three diode model for industrial solar cells and estimation of solar cell parameters using PSO algorithm. Renewable Energy, 78, 105-113.

Li, S., Gong, W., Yan, X., Hu, C., Bai, D., Wang, L., \& Gao, L. (2019). Parameter extraction of photovoltaic models using an improved teaching-learning-based optimization. Energy Conversion and Management, 186, 293-305.

Liu, L., Meng, X., \& Liu, C. (2016). A review of maximum power point tracking methods of PV power system at uniform and partial shading. Renewable and Sustainable Energy Reviews, 53, 1500-1507. 
International Journal of Mathematical, Engineering and Management Sciences

Vol. 6, No. 3, 911-931, 2021

https://doi.org/10.33889/IJMEMS.2021.6.3.054

Louzazni, M., \& Aroudam, E.H. (2015). An analytical mathematical modeling to extract the parameters of solar cell from implicit equation to explicit form. Applied Solar Energy, 51(3), 165-171.

Lu, C., Xiao, S., Li, X., \& Gao, L. (2016). An effective multi-objective discrete grey wolf optimizer for a real-world scheduling problem in welding production. Advances in Engineering Software, 99, 161-176.

Ma, J., Ting, T.O., Man, K.L., Zhang, N., Guan, S.U., \& Wong, P.W. (2013). Parameter estimation of photovoltaic models via cuckoo search. Journal of Applied Mathematics, 2013.

Ma, T., Yang, H., \& Lu, L. (2014). Development of a model to simulate the performance characteristics of crystalline silicon photovoltaic modules/strings/arrays. Solar Energy, 100, 31-41.

Mirjalili, S., Mirjalili, S.M., \& Lewis, A. (2014). Grey wolf optimizer. Advances in Engineering Software, 69, 46-61.

Mohapatra, A., Nayak, B., Das, P., \& Mohanty, K.B. (2017). A review on MPPT techniques of PV system under partial shading condition. Renewable and Sustainable Energy Reviews, 80, 854-867.

Oliva, D., El Aziz, M.A., \& Hassanien, A.E. (2017). Parameter estimation of photovoltaic cells using an improved chaotic whale optimization algorithm. Applied Energy, 200, 141-154.

Panwar, N.L., Kaushik, S.C., \& Kothari, S. (2011). Role of renewable energy sources in environmental protection: a review. Renewable and Sustainable Energy Reviews, 15(3), 1513-1524.

Ram, J.P., Manghani, H., Pillai, D.S., Babu, T.S., Miyatake, M., \& Rajasekar, N. (2018). Analysis on solar PV emulators: a review. Renewable and Sustainable Energy Reviews, 81, 149-160.

Rezk, H., Babu, T.S., Al-Dhaifallah, M., \& Ziedan, H.A. (2021). A robust parameter estimation approach based on stochastic fractal search optimization algorithm applied to solar PV parameters. Energy Reports, 7, 620-640.

Rhouma, M.B., Gastli, A., Brahim, L.B., Touati, F., \& Benammar, M. (2017). A simple method for extracting the parameters of the PV cell single-diode model. Renewable Energy, 113, 885-894.

Sharma, A., Pachauri, R., Sharma, A., \& Raj, N. (2019). Extraction of the solar PV module parameters using chicken swarm optimization technique. Paper presented at the 2019 Women Institute of Technology Conference on Electrical and Computer Engineering (WITCON ECE), (pp. 45-48). IEEE. Dehradun Uttarakhand, India.

Sharma, A., Sharma, A., Averbukh, M., Jately, V., \& Azzopardi, B. (2021). An Effective method for parameter estimation of a solar cell. Electronics, 10(3), 312.

Soon, J.J., \& Low, K.S. (2012). Photovoltaic model identification using particle swarm optimization with inverse barrier constraint. IEEE Transactions on Power Electronics, 27(9), 3975-3983.

Subudhi, B., \& Pradhan, R. (2017). Bacterial foraging optimization approach to parameter extraction of a photovoltaic module. IEEE Transactions on Sustainable Energy, 9(1), 381-389.

Tao, Y., Bai, J., Pachauri, R.K., \& Sharma, A. (2020). Parameter extraction of photovoltaic modules using a heuristic iterative algorithm. Energy Conversion and Management, 224, 113386.

Tsai, P.W., \& Dao, T.K. (2016). Robot path planning optimization based on multiobjective grey wolf optimizer. Paper presented at the International Conference on Genetic and Evolutionary Computing, 166-173. Springer, Cham. Fuzhou City, Fujian Province, China.

Villalva, M.G., Gazoli, J.R., \& Ruppert Filho, E. (2009). Comprehensive approach to modeling and simulation of photovoltaic arrays. IEEE Transactions on Power Electronics, 24(5), 1198-1208.

Wei, H., Cong, J., Lingyun, X., \& Deyun, S. (2011). Extracting solar cell model parameters based on chaos particle swarm algorithm. Paper presented at the 2011 International Conference on Electric Information and Control Engineering. (pp. 398-402). IEEE. Wuhan, China.

Youssef, A., El-Telbany, M., \& Zekry, A. (2017). The role of artificial intelligence in photo-voltaic systems design and control: a review. Renewable and Sustainable Energy Reviews, 78, 72-79. 